\title{
Protection of Design Patents in China and Comparison with European Union Law: How Foreign Companies Can Protect Their Design Patents in China
}

\author{
Alice Graneris \\ KoGuan Law School, Shanghai Jiao Tong University, Shanghai, China \\ Email: alice.graneris@outlook.com
}

How to cite this paper: Graneris, A. (2019). Protection of Design Patents in China and Comparison with European Union Law: How Foreign Companies Can Protect Their Design Patents in China. Beijing Law Review, 10, 212-238.

https://doi.org/ 10.4236/blr.2019.101013

Received: February 15, 2019

Accepted: March 15, 2019

Published: March 18, 2019

Copyright () 2019 by author(s) and Scientific Research Publishing Inc. This work is licensed under the Creative Commons Attribution International License (CC BY 4.0).

http://creativecommons.org/licenses/by/4.0/

\begin{abstract}
This paper is mainly focused on a specific aspect of Chinese intellectual property law: design patents and utility models related to foreign companies, especially in automotive and fashion industries. It aims to analyze and examine the protection of design patents and utility models featuring in foreground real cases in China and involving foreign companies, especially European and Italian companies. Holders of intellectual property rights and possible solutions to their cases are the focus and objective of this paper: how foreign companies can face these issues through the existing Chinese intellectual property law and, when Chinese law is not satisfactory enough or when there is a lack, trying to find new possible solutions and suggestions which might be beneficial for foreign companies. Considering interests and concerns which involve foreign companies and their products in the subject matter, Chinese intellectual property law has evolved in the past few years in order to safeguard foreign companies from infringement of their rights, which became quite frequent. Currently the aim of Chinese intellectual property law is not only to prevent lawsuits between foreign and local companies, but also the infringement itself by local companies. Comparing Chinese intellectual property law with European provisions concerning intellectual property rights system, the objective is trying to understand the differences and mostly the advantages that one system can show more than the other one, finding new strategies and remedies, such as updates and solutions that might be useful to insert in the current Chinese intellectual property system and which might be efficient and functional for foreign companies' business in China as well as to protect their intellectual property rights in the best way.
\end{abstract}




\section{Keywords}

Design Patent, Intellectual Property, Intellectual Property Rights, Chinese IP Law, Patents

\section{Introduction}

Holders of intellectual property rights, specifically design patents, and possible solutions to their cases are objective of this paper: how foreign companies can face these issues through the existing Chinese intellectual property law and, when Chinese law is not satisfactory enough or when there is a lack, trying to find new possible solutions and suggestions which might be beneficial for foreign companies.

Above all, automotive and fashion industries have experienced the common situation of infringement of their intellectual property rights in China. Considering interests and concerns which involve foreign companies and their products in the subject matter, Chinese intellectual property law has evolved in the past few years in order to safeguard foreign companies from infringement of their rights, which became quite frequent.

Currently the aim of Chinese intellectual property law is not only to prevent lawsuits between foreign and local companies, but also the infringement itself.

Comparing Chinese intellectual property law with European provisions concerning intellectual property rights system, the objective is trying to comprehend the differences and mostly the advantages that one system can show more than the other one, finding new strategies and remedies, such as updates and solutions that might be useful to insert in the current Chinese intellectual property system and which might be efficient and functional for foreign companies' business in China as well as to protect their intellectual property rights in the best way.

\section{Design Patents and Chinese Context}

\subsection{Intellectual Property in Chinese Background}

The design patent was first introduced in China in 1985 as part of the country's first modern patent system, which also included the invention patent and the utility model patent, while design patent protection in China is established under the Patent Law and the Implementing Regulations of the Patent Law: generally speaking, designs patents cover new designs, shapes, patterns, or colors, which are rich in an aesthetic appeal and are fit for industrial application (Timoteo, 2010).

Conversely, the invention patent protects technical solutions or improvements relating to products or processes, while the utility model patent covers mostly structures and shapes of mechanical structures (Moga, 2012).

Since its introduction, the design patent has been enthusiastically embraced by 
Chinese entities. Design patent is preferred over the invention patent by Chinese applicants, they are even generally cheaper to apply for, granted faster, and contain a relatively broad scope of coverage, while the invention patent is more expensive and takes longer to process.

On the other hand, foreigners in China have not been so enthusiastic, having filed just over 10,000 design patent applications in 2011, or about 11 percent of all types of patents filed by foreign applicants. While some foreign companies are building their design patent portfolios in China, many other foreign companies believe that the enforcement system in China is weak, and that PRC government is not truly committed to protecting intellectual property rights (IPRs).

At the present time China's intellectual property enforcement system is extensively improved, comparing to how it once was, although much more work needs to be done to lead China's enforcement regime to a world-class level. Supposing that this path is continuous and stable, a protected design patent today will potentially have a better chance of being enforced in the nearest future.

Some scholars have analysed this specific topic in intellectual property law and related issues, highlighting the importance of the relationships between the economic development and the protection of intellectual property rights.

Indeed, since the late 1980s, the Chinese economy has been growing at an enviable average annual rate of about 10 per cent: together with this unprecedented economic development and growth there was the maturation of the modern Chinese intellectual property system, and since the late 1970s, during the reopening of its market to foreign trade, China introduced its first modern intellectual property laws including copyright, patent, and trademark laws. A decade later, China renovated and revised its intellectual property system in response to US pressure and in the light of its preparation to accession to the WTO.

At present, China is a proud member of many multilateral intellectual property agreements; whilst these developments, the enforcement of intellectual property rights are still quite weak. In spite of the fact that commentators frequently relate intellectual property protection system to economic development, China has presented a puzzle up to now to those scholars who analyse this connection.

While some commentators consider China a model case for showing that rapid economic development can take place despite rather limited intellectual property protection, others have noted gradual improvements in the Chinese intellectual property system as the country became more economically developed, and it is only a matter of time before China is converted to a nation that fully respect intellectual property rights.

The analysis of relationship between intellectual property protection and economic development begins by exploring the conventional linkage between intellectual property protection and foreign direct investment.

Scholars took in exam why China expanded its intellectual property protection even though such expansion was unnecessary for attracting foreign investments, and they also point out the country's regional and sectoral disparities, its 
inadequate development of an enabling environment for effective intellectual property protection, and its improvements in intellectual property protection at both the microscopic and qualitative level (Raustiala \& Sprigman 2014).

The outcome is that a better understanding of the role of intellectual property protection in promoting economic development will provide a more accurate forecast of when China will reach a crossover point at which it will find stronger intellectual property protection in its self-interests.

Another relevant issue concerning this topic, that also has much influence in Chinese background, is the source of China's ambivalence toward intellectual property rights, and it has to be taken in consideration when analysing these rights.

Many analysts point to cultural factors, in particular the powerful legacy of Confucian thinking (Timoteo, 2010). According to this point of view, China has a distinctive historical relationship to copying that puts it at odds with the model of private ownership of creative goods that is deeply embedded in contemporary Western, and by extension international, intellectual property law.

In this context, analyses of China's not-easy relationship to intellectual property law often quote Confucius ${ }^{1}$ famous dictum "I transmit rather than create" (Raustiala \& Sprigman, 2014).

It is sometimes suggested that this statement became an influential guiding principle in later centuries; as one scholar of China has argued, "the incorporation of elements of past works in one's own was not undertaken with the intent to steal another author's ideas. Rather, imitation was the means for authors to demonstrate their knowledge and mastery of history; it was a form of tribute to their predecessors" (Tze-Hun Chou, 1997).

A similar analysis states that IP law as it has been conceived in the West "goes firmly against the grain of Asian culture, which supports the concept of sharing, not protecting, individual creative work"; particularly, according to some commentators, IP is a "cultural phenomenon as well as an economic one" (Raustiala \& Sprigman, 2014).

However some countries, like China, showing a so called "collective" culture, in other words a culture that rather emphasizes sharing over individual ownership rights, have importantly higher rates of copying and counterfeiting than ${ }^{1}$ Confucius, 551-479 BC, was a Chinese teacher, editor, politician, and philosopher of the Spring and Autumn period of Chinese history. The philosophy of Confucius, also known as Confucianism, emphasized personal and governmental morality, correctness of social relationships, justice and sincerity. His followers competed successfully with many other schools during the Hundred Schools of Thought era only to be suppressed in favor of the Legalists during the Qin dynasty. Following the victory of Han over Chu after the collapse of Qin, Confucius's thoughts received official sanction and were further developed into a system known in the West as Neo-Confucianism, and later New Confucianism (Modern Neo-Confucianism). Aphorisms concerning his teachings were compiled in the Analects, but only many years after his death. Confucius's principles have commonality with Chinese tradition and belief. He championed strong family loyalty, ancestor veneration, and respect of elders by their children and of husbands by their wives, recommending family as a basis for ideal government. Confucius is widely considered as one of the most important and influential individuals in shaping human history. His teaching and philosophy greatly impacted people around the world and remains influential today. 
countries traditionally showing "individualist" cultures.

China's devotion for the past has not always been felt in a consistent way: after 1949, Mao specifically tried to discredit the past as a source of legitimacy, having the perception that China's ancient cultural legacy could have been a source of oppression and cause of backwardness.

Even Confucius himself earned disapproval at that time: during the Cultural Revolution that followed, the "Four Olds"-Old Customs, Old Habits, Old Culture, and Old Ideas-were vilified and defamed. However this rejection of the old wisdom and ideas didn't mean to lead to the end of copying, nor it didn't implicate the acceptance and embrace of western notions of intellectual property.

Certainly, all kinds of property were considered as anathema in China, during Mao's epoch. Indeed, it was only following the Cultural Revolution period, as Mao's influence waned and China began to open up again to the West, that Chinese leaders began slowly and slowly to embrace Western views and approaches to IP.

China passed its first post-revolutionary patent and trademark laws in the 1980s, and its first copyright law in 1990 (Timoteo, 2010). Simultaneously, the Chinese leadership laid the groundwork for the country's extraordinary economic growth: such economic growth has been fostering China's contemporary culture of copying.

In the decades since Deng Xiaoping's supposed dictum "to get rich is glorious", China has experienced unprecedentedly rapid development, as well as an unleashing of the entrepreneurial and acquisitive talent that had long marked China before.

Actually in China, more than in other countries with longstanding wealth, luxury goods seem to get a grand cultural prominence. At another level, however, it is not just the economy that is changing: mores about wealth and its display have also changed markedly.

Since the Chinese economy has grown at unprecedented rates and Chinese people generally have become wealthy, the relevant interest in the causes that have triggered admiration for luxury has grown, as well as signals of class distinction.

Still, some observers believe that the Chinese admiration and passion for luxury, likewise its proclivity for copying, is guided by peculiar and quite unique cultural factors. For example, some scholars believe that generally consumers in Asia purchase luxury goods to secure social recognition and to show their status because the culture emphasizes hierarchy and status (Raustiala \& Sprigman, 2014).

The concept of "face" or mianzi appears large and widespread in many of these analyses based on the relevant culture: as another observer argues, "Due to the heavy influence of face, Asian consumers must purchase luxury products to enhance, maintain or save their face. Therefore, the conceptualisation of face and face consumption provides a useful way to understand why Asian consum- 
ers, on the one hand, are very thrifty in their everyday life and consumption but, on the other hand, spend (and sometimes waste) a large amount of money on luxury consumption" ( $\mathrm{Li} \& \mathrm{Su}, 2007)$.

From this perspective, a culturally-determined fascination for wealth and wellness, pushes Chinese citizens to seek out luxury goods that are visible and recognizable to others. Obviously buying luxury goods requires means, and the argument that there is something special in Chinese culture, rather than China's stage of economic development, that focuses the attention of Chinese consumers on luxury goods involve the concept of mianzi.

Mianzi may well reflect distinctively Chinese, or East Asian, cultural concerns, but it may be also a reflection of the broader concept of status, which seems to be an almost universally-human obsession (Raustiala \& Sprigman, 2014).

It is definitely clear that for China's huge numbers of newly-rich, or newly-middle class, Western brands often serve as instant and very desirable social signifiers of success.

An additional distinguishing aspect of contemporary China deserves a wider attention: the exceptional Chinese concept of shanzhai.

Shanzhai means literally "mountain stronghold" or "bandit stronghold" (Raustiala \& Sprigman, 2014), however, in contemporary usage, it refers to low-cost knockoffs, such as buildings, stores and even events: in China Shanzhai is significant especially for comprehending luxury goods as well as counterfeits, because shanzhai culture combines the strong desire for wealth with copying of luxury goods, and makes first production and also consumption of counterfeit products socially legitimate and rightful.

Once Shanzhai connoted poor imitations of desirable originals, but like so much else in China, the term's meaning has undergone change as China itself changed.

Shanzhai cell phones, consumers' household products, fashion items, and even fast food restaurants are numerous, and in China today these goods are often indicated with pride and recommended too.

The popular esteem and admiration of shanzhai products result in a challenge for anti-counterfeiting efforts and, apparently faraway from restraining the phenomenon, the Chinese government seems to believe that shanzhai-style creativity is something to cultivate instead, and indeed Chinese authorities seem to recognize that shanzhai is socially intrinsic, and it seems unlikely to disappear (Raustiala \& Sprigman, 2014).

In a culture where copying had, especially in the past years, social value in society, the widespread availability of shanzhai products may be useful as a deterrent on the social unrest that contemporary China's level of social inequality tends to create, by allowing access to versions of the products that only wealthy people can afford in their original form.

Another reason that Chinese leaders may tolerate shanzhai is that they are not the only or even primary target: indeed shanzhai can also be a way for ordinary Chinese to challenge global authority, in particular the continuing economic 
dominance of the West. China's vibrant shanzhai culture embraces a range of activities from the homemade to the high tech products and goods.

Regardless, copying is celebrated perhaps as much as it is condemned, and China continues to innovate even as it imitates.

In this context the turning point was when China joined the U.N. specialized agency WIPO on March 3, 1980 and became a member three months later. ${ }^{2}$

Moreover, in December 2001 China became the 143rd member of the World Trade Organization (WTO). Such membership requires the country to, among other obligations, abide by the Agreement on Trade-Related Aspects of Intellectual Property Rights' (TRIPS Agreement) ${ }^{3}$, the most comprehensive intellectual property agreement ever adopted by the international community.

In the past decade, China has also actively participated in the negotiation of bilateral, regional, and multilateral trade agreements (Yu, 2018).

While the previous phase covered the customization and standardization efforts before China's WTO accession, the following phase was focused on post-accession developments.

Notwithstanding the continuity from the pre-accession phase to the post-accession phase, this one separates scholars in the customization and standardization phase, from scholars in the integration and assimilation phase. Such separation makes salient the latter's focus on China's integration efforts and legal and policy responses following WTO accession (Yu, 2018).

For instance, a significant volume of scholarship in the integration and assimilation phase analyzed the amendments China adopted shortly before WTO accession: these amendments included also the Second Amendment to the Patent Law, in August 2000, (as well as the First Amendment to the Copyright Law and the Second Amendment to the Trademark Law, which China adopted in October 2001).

One major strand of scholars focusing on the ongoing discussion of independent innovation has caused concerns regarding the innovation models and innovative capabilities of Chinese companies, especially those of the national champions in the high-technology area. ${ }^{4}$

An additional, but limited, strand of scholarship in this phase pertains to ${ }^{2}$ World Intellectual Property Organisation (WIPO) is the global forum for intellectual property services, policy, information and cooperation and agency of the United Nations, with 191 member states.

${ }^{3}$ Agreement on Trade-Related Aspects of Intellectual Property Rights, Apr. 15, 1994.

${ }^{4}$ As Daniel Chow explained: “One key goal of [China's indigenous innovation policies] is to develop 'national champions': Chinese companies that aspire to compete effectively with the largest and most powerful multinational companies... in the world today. Since innovation and advanced technology are crucial requirements of competitiveness in the modern global economy, a key component of these strategies is to spur Chinese entities to develop the capacity to create innovative and advanced technologies... In China's view, it can never ascend to the leading ranks of industrialized nations if it continues to be a recipient or importer of advanced technologies or IP created by innovator countries, such as the United States. Innovator countries are often reluctant to provide access to their 'core' technologies but often only provide access to their secondary technologies in order to preserve a competitive advantage. China wants to become a leading innovator country in its own right and does not want to depend on access to technology from the United States, Japan, and western European nations, which now dominate the area of technology innovation." 
China's changing position in the international trading and intellectual property systems (Yu, 2018).

As China is slowly moving from its often discussed roles of a "norm-taker" to the new roles of a "norm-maker", this literature has become quite significant, not only because of the legal considerations and from a legal standpoint, but also because of economic and political considerations.

Today, Chinese intellectual property system has garnered considerable global policy and scholarly attention; furthermore, based on the statistics compiled by the World Intellectual Property Organization (WIPO), China had the world's second largest number of international applications filed through the Patent Cooperation Treaty ${ }^{5}$ in 2017, behind only the United States (Yu, 2018).

As already discussed, Chinese philosophy and culture has been an important entry point to understanding not only intellectual property law and policy in China, but also the Chinese legal system in general. It is not uncommon for scholars in both areas to discuss the historic distinction between li (rituals or rites) and $f a^{6}$ (law and punishment) in Chinese culture.

Such distinctions trace back to the age-old tension between Confucianism ${ }^{7}$ ${ }^{5}$ Patent Cooperation Treaty, June 19, 1970.

${ }^{6}$ The word for 1 aw in classical Chinese was fã (法). The Chinese character for fã denotes a meaning of "fair", "straight" and "just". Confucianism and Legalism are two major Classical legal theories or philosophies developed during the Spring and Autumn period and the Warring States period, a time that saw the most impressive proliferation of new ideas and philosophies in Chinese history. While both theories call for governmental hierarchy, they differ drastically in their views of human potential and the preferred means to achieve political order. Nevertheless, both theories have influenced and continue to influence the development of cultural, social, and legal norms in China. The basic premise of Confucianism is the idea that human beings are fundamentally good. With this optimistic view on human potential, Confucius advocates for ruling through $l i$-traditional customs, mores, and norms-which allow people to have a sense of shame and become humane people with good character, rather than through government regulations and penal law. In contrast, codified laws require external compliance, and people may abide by the laws without fully understanding the reason for compliance. As Confucius rejects the general use of formal laws to achieve social order, what lies vital to Confucius' theory is the willing participation by citizens of the society to search for commonly accepted, cooperative solutions. In addition to willing participation of citizens, there must also be grounds or bases upon which commonly acceptable solutions can be arrived at - the concept known as $l i$. $L i$ is commonly understood as a set of culturally and socially valued norms that provide guidance to proper behaviors that will ultimately lead to a harmonious society. These norms are not fixed or unchangeable over time but rather a reflection of what is accepted at a particular time in a particular context. When conflicts arise, the li have to be applied and interpreted to produce a just result and restore the harmony of the society. However, in the absence of any procedural safeguard afforded by codified laws, interpretation of $l i$ is subject to abuse. In contrast to Confucius' $l i$-based theory, the Legalism advocates the utilization of codified laws and harsh punishment to achieve social order. This is due to the legalists' belief that all human beings are born evil and self-interested.

${ }^{7}$ One of the seminal works on the Chinese intellectual property system is William Alford's To Steal a Book Is an Elegant Offense. Professor Alford's culture-based argument is: "The strong form states that Confucianism militates against intellectual property reforms in China. It accounts for the failure of the many reforms pushed by foreign countries and intellectual property rights holders to induce improvements in intellectual property protection and enforcement ... [By contrast, the weak form ... states that Confucianism has prevented the Western notion of intellectual property rights from taking root in China ... [It] does not suggest any incompatibility between Confucianism and the Western notion of intellectual property rights. Nor does it contend that Confucianism will militate against intellectual property reforms.] Thus, if such reforms are to be introduced-either internally through the borrowing of foreign ideas or externally in response to foreign pressure-these reforms may help China establish an exogenously developed intellectual property system.” 
and Legalism: while the first one focuses on normative roles, responsibilities, obligations, and a wide range of political, social, and familial relationships, the latter sought to use criminal law, physical punishment, threats, and coercion to maintain public order ( $\mathrm{Yu}, 2018)$. As far as such culture is concerned, Confucianism provides the immediate jumping off point for intellectual property scholars. Indeed, a considerable volume of scholars on Chinese intellectual property system has been devoted to the Confucian impact on intellectual property reforms: while this type of scholars has provided culture-based analyses that are both insightful and appealing to Western readers, on the other hand an exclusive focus on Confucianism would create a rather incomplete picture of the impact of Chinese culture on intellectual property developments.

While the analysis of the philosophical basis of Chinese intellectual property law and policy has thus far remained limited to only scholars with deep knowledge of Chinese philosophy or culture, a better linkage between the notions of intellectual property rights and such philosophy or culture can be beneficial ( $\mathrm{Yu}$, 2018).

Moreover, another area worth highlighting concerns economic issues relating to intellectual property protection and enforcement in China and its relations with the country's growing intellectual property industries (Timoteo, 2010). These issues include economic growth, industrial development, technological innovation, and foreign investment: they are of great interest to economists, researchers in business and especially focusing on innovation and creative industries.

Economists have shown how stronger intellectual property protection could lead to an increase in foreign direct investment. Their research demonstrates that such a positive link requires the presence of two key preconditions: a strong imitative capacity and a large market. China possesses both, but weak intellectual property protection could undermine, and has undermined, China's appeal to foreign investors.

While economic research has been essential to the intellectual property field, comparative research can provide especially valuable insight into the appropriate international minimum standards for both protection and enforcement of intellectual property rights.

As China has become the global center for many different stages of production, it has also developed a formidable competitive capacity to innovate in different segments of the research, development, and production chain that are as critical for economic growth as many novel-product innovations, and perhaps even more so. In addition, taken together, China's regional and national systems have developed varied capabilities that amount to a specific and highly successful, though inadvertently, created national model (Yu, 2018).

China's accomplishment has been to overcome the art of flourishing in second-generation innovation-including the mixing of established technologies and products in order to come up with new solutions-and the science of organizational, incremental, and process innovation. Thus, China's innovation capabil- 
ities are not solely in process (or in increasing) innovation but also in the organization of production, manufacturing techniques and technologies, delivery, design, and second-generation innovation. Those capabilities enable China to move quickly into new niches once they have been proved profitable by the original innovator.

One topic that has received only limited, but slowly growing, coverage is China's role in the international intellectual property regime. This topic is what brought international relations scholars to this area: there has been a growing volume of scholarship on China's increasing role in the international trading system. Thanks to the marriage of intellectual property with trade via the TRIPS Agreement and China's growing emphasis on independent innovation, this role has an increasingly important intellectual property component (Huang, Geng, \& Wang, 2017).

Furthermore, with the adoption of TRIPS, the increased relevance of internet-based activities, and the raising profile of intellectual property research, scholars have paid growing attention to developments in the intellectual property area. As scholars become more interested in this area, some of them have also chosen to conduct research on the Chinese intellectual property system.

\subsection{Patent Law Regulations in China}

China reports rapid increase in design patent applications during the past few years (Crouch, 2010).

China adopted the first version of Patent law in 1984, Standing Committee of the Sixth National People's Congress. It was amended for the first time in accordance with the Decision of the Standing Committee of People's Congress in 1992, amended for the second time in accordance with the Decision of the Standing Committee in 2000, and amended for the third time on $27^{\text {th }}$ December 2008.

The latest amendment follows the new phase that Chinese government was willing to implement, focusing on innovation (Timoteo, 2010). Key word of this period was exactly innovation, and fundamental objectives were scientific and technologic development.

China wanted to become an innovating country, and starting from those years, around 2000, the number of Chinese companies applying for patent registration increased a lot, more than foreign companies applying for patents registration in China.

The new regulation provides three types of patents in China: invention, utility models and design patents.

According to Patent Law of RPC, inventions are "new technical solutions proposed for a product, a process or the improvement thereof" (Patent Law of People's Republic of China, art. 2).

Utility models are specifically defined as "new technical solutions proposed for the shape and structure of a product, or the combination thereof, which are fit for practical use". While patent designs are established: "with respect to a 
product, new designs of the shape, pattern, or the combination thereof, or the combination of the color with shape and pattern, which are rich in an aesthetic appeal and are fit for industrial application" (Patent Law of People's Republic of China, art. 2).

Design patents typically involve visual images. When assessing similarity in an infringement proceeding, visually perceived images are necessarily "translated" into verbal expression (Beldiman \& Beconcini, 2015).

The Patent Law of the Republic of China provides that the owner of a design patent may prevent third parties from making, offering for sale, selling or importing a product that incorporates, the patented design, for purposes of production or business, without the consent of the rights' holder.

Generally speaking, the protection of an invention patent covers both the process and product characters. The utility patent covers most technical fields of product character, except for sonic, light, electric and gas requirements acting on the human body. Finally, the design patent covers only characteristics such as shape, colour, etc. Industrial application if fundamental requirement: if the requirement of applicability is not met, the patent won't be granted (Timoteo, 2010).

For an invention patent, one must pass two examination processes. The first examination is called the process examination and the second is called the substantial examination. In the process examination, the examiner only considers the contents of the process requirements such as the quantity and type of documentation, etc. In the substantial examination, however, the examiner analyses the innovation, creativity and use of the patented item. This examination process usually takes about three years to complete before receiving an invention patent. For a utility patent, usually one only needs to pass the process examination. This application process usually takes between six months and one year to complete before a utility patent can be awarded.

The design patent is the easiest to obtain, since it is based upon establishing some difference in the patented item's shape, colour, etc., and it is commonly requested and used in automotive and fashion industries.

In China, there are essentially two different alternatives which parties can utilize to resolve patent disputes. There is the non-legal, optional pathway, and there is the legal pathway leading either to court or to an administrative department. In the optional procedure, the parties try to resolve the issues by themselves or through their patent attorneys. This procedure appears to work well when there are minor issues and benefits involved. However, when major issues are contested, such as when technical or legal conditions are not clear or not well defined, the optional process does not work (Ou, 1996).

In the legal procedure, disputants can choose between an administrative solution or going to court: the decision to choose either court or an administrative department is optional and up to the parties. As example, one party goes to the administrative department, then the decision is reviewable by the courts. If one goes to court, however, the decision is final unless appealed. It is also possible to 
go to both the administrative department and the court simultaneously. One of the best ways to win a suit is to use local counsel, even if China's patent and economic litigation system is quite young. Chinese patent attorneys and lawyers have made excellent strides, but still need to improve the system so as to be more beneficial for the Chinese people. These professionals welcome new ways to reduce the time necessary to conduct and complete patent examinations, while maintaining the quality of the process and its fairness.

There have been numerous reports on IPRs infringements by Chinese companies, leading to doubts on China's ability to protect IPRs.

It is Chinese tradition to encourage competition in order to enhance innovation and improvement, especially using their intellectual property rights.

To IPRs infringement has a huge impact on the economy in China and the world: Chinese companies' innovations are repressed because of piracy, and many foreign investors lose confidence in dealing with Chinese companies. Also, in this way competition and innovation is reduced (Man, 2013).

To many, competition and IP law appear to conflict with each other. In fact, they can be complementary and share similar policy goals, such as encouraging innovation and development, and enhancing consumer welfare.

It is argued that competition law can help enhance IP protection. Both competition and IP law aim to protect IPRs in order to facilitate innovation and encourage investment in researching and developing more new ideas. IP law, in particular, facilitates the commercialisation of innovation and encourages public disclosure when the IPR owner registers its IPR.

IP law recognises the value of competition by limiting the life and breadth of IPRs, while competition law recognises that an effective legal regime of IPRs is essential to a competitive economy.

In this context, the Anti-Monopoly Law ${ }^{8}$, enacted in 2008, becomes relevant: it is one of three statutes that protect competition in the Chinese markets, and some scholars describe it as an economic constitution. The Anti-monopoly law aims to prevent and restrain monopolistic conduct, promote fair competition, enhance economic efficiency, safeguard consumer and social public interests, as well as promote a healthy development of the socialist economy, thus protecting small and medium enterprises from larger competitors. The approach of the Anti-monopoly Law accords with other international approaches and reflects global concerns (Man, 2013).

Article 55 of the Anti-monopoly Law, which is under the chapter on Supplementary Provisions, is particularly related to IPRs, and it states that: "This Law does not govern the conduct of business operators to exercise their intellectual property rights under laws and relevant administrative regulations on intellectual property rights; however, business operators conduct to eliminate or restrict market competition by abusing their intellectual property rights shall be gov-

\footnotetext{
${ }^{8}$ Anti-monopoly law of the People's Republic of China, was adopted at the 29th meeting of the Standing Committee of the 10th National People's Congress of the People's Republic of China on August 30, 2007.
} 
erned by this Law" (Anti-monopoly Law, art. 55).

The first half of Article 55 sets out an exemption from the application of the Anti-monopoly Law, which IPR owners are not subject to such scrutiny for merely exercising their IPRs consistent with the laws and relevant administrative regulations on IPRs, however under a condition: if they engage in any conduct that seeks to eliminate or restrict market competition by abusing their IPRs, then, the this law shall apply (Man, 2013).

The language adopted in AML is very general, including Article 55, and certain key terms are not defined, such as to what constitutes to eliminating or restricting market competition, IPRs, or the abuse of IPRs. The AML does not explicitly repeal but coexists with many existing applicable Chinese competition and IP laws and regulations.

The legal and regulatory protection of IPR, such as patent laws, is one of the most important aspects of formal institutions. IPR facilitates firms' innovative activities by providing protection against expropriation, therefore increasing the incentives for firms to innovate and grow.

\section{Infringement Cases and Relevant Decisions}

\subsection{Intellectual Property Rights Infringements Context}

China has experienced significant growth in the number of filed patent applications over the last 10 years.

Over the past few years, PRC courts have witnessed remarkable infringement actions which have involved design patents, but it still remain not very clear how similar an accused product has to be, and in which way, before it is found to be infringing (Moga, 2012).

In January 2010 the Supreme People's Court issued an interpretation establishing that, to ascertain an infringement in a specific case, an "eye of the ordinary beholder" test will be applied to determine whether there is substantial similarity or not. The purpose of the Supreme Court was to try providing guidance to courts.

This mentioned "ordinary beholder" must carry out a "comprehensive assessment" of the overall characteristics of the cited designs when determining whether or not there is adequate and plausible likeness to support an actual finding of infringement.

However, previous courts' decisions suggest that handling of similarity by Chinese courts, especially with regard to some certain past cases that will be analysed hereinafter, remains quite contradictory.

Design patent infringement litigation raises the complex issue of assessing the degree of similarity in the appearance of two products. However, some fundamental questions relating to the analysis remain unresolved (Beldiman \& Beconcini, 2015).

The relative weight of individual elements is closely related to the proper lens to be applied to the analysis: whether the observer should "zoom in" identifying 
each element of the design and then compare the similarities and differences of each element individually, or rather should the observer "zoom out" to form a holistic view of the designs as a whole and then determine similarity.

The choice of lens has strategic implications. Indeed, patent holders tend to advocate a "design as a whole" approach. Alleged infringers typically advocate an elemental analysis, seeking to elevate minor details to the status of similarity-destroying differences (Beldiman \& Beconcini, 2015).

It is a fundamental rule that in comparing a design, only the design's protectable elements are to be considered and any non-protectable design features are to be disregarded. On the other hand, the law also mandates that competing designs be compared in their entirety.

Under a "design as a whole" view, non-protectable aspects would have to be included when determining similarity, thus unjustifiably broadening the scope of protection beyond the scope to which the patentee is entitled. On the other side, if these aspects are to be excluded, the fact finder is faced with a truncated version that bears no resemblance to the protected design.

Besides, a certain amount of subjectivity is inevitable in comparing designs: individuals form unique, subjective reactions to visual images, inevitably also when it comes to judges in courts.

Consequently, the absence of more precise standards for determining whether a product is identical or similar to a patented design, has resulted in not very reasonable court decisions and has prevented the development of clear and fair standards for infringement determination.

\subsection{Jurisprudence and Courts' Interpretations}

The jurisprudence of the early years following the enactment of the 2001 amendment to patent law tended to follow an element-by-element approach to design similarity.

As example, in 2003, Honda brought a case against Chinese automotive company Heibei Shuanghuan" alleging that the Chinese automotive company "Laibao S-RV" infringed its design patent for the C-RV model. The case went through the proceeding until before the Supreme People's Court.

The defendant Heibei company, claimed that the mentioned Honda's patent, the C-RV design, was known and therefore was shown in the "prior art" before Honda applied for patent protection itself (Moga, 2012).

The court determined that, in this case, in matter of sedans a review of the overall view of the vehicle doesn't help because sedans generally have common configurations.

In cases like this one, the "ordinary consumer" is able to distinguish between particular products by distinguishable specific features, such as headlamps for example, and that certain design features were used to determine brand identity.

This traditional view, embodied in the 2001 Opinions of the Beijing Higher ${ }^{9}$ Honda vs. Heibei Shuanghuan, (2003), Beijing High People's Court, China.

${ }^{10}$ Opinions on Several Issues Relating to Patent Infringement Establishment, (2001), No. 229 Jing Gao Fa Fa. 
Court, ${ }^{10}$ was then confirmed by the 2009 judgment of the Shijiazhuang Higher Court in the Fiat Panda case. ${ }^{11}$

In that case, the Court held that the existence of a single different design feature, in comparing designs, or the absence thereof is sufficient to deny similarity, even in case the two designs may look similar based on an overall and all-round observation.

In this decision the Court considered that the front view of a vehicle is most significant and that a change to the front grille would eliminate the similarity of the two vehicles in that the grille was an essential element to the Fiat Panda design (Beldiman \& Beconcini, 2015).

However, the court disregarded other relevant features on the design patent's side, such as the originality of the side view of the Fiat Panda, its rear views and side roofline, compared to the prior art.

The fact that the court was not obliged by any provision to confirm its determination of which features were essential or not essential, by referring to only the overall visual effect of the designs under comparison, left the judges with substantial discretion, as well as determining and defining the scope of protection of the design patent.

This comparison resulted in a decision of non-infringement in favour of the defendant. The defendant, merely by adding or slightly reshaping features in order to differentiate their design from patented design, was not convicted eventually, despite the fact that the overall visual impression of the two designs was one of similarity.

In 2009, the Supreme Court issued a new interpretation ${ }^{12}$, and in its articles 10 and 11 specific governing criteria to be used by all People's Courts in determining design patent infringement are listed.

The Interpretation makes clear that infringement must be assessed in consideration of the level of knowledge and understanding of the relevant average consumer of the claimed design. When making this determination, a court must take into account the overall visual impression formed by the design features, which are within the design patent's scope of protection.

Thus the relation "identity and similarity" between the claimed and the accused designs is assessed based on the designs' overall visual effect: importance is given to elements, which are more readily visible to the observer when the product is in use, and mostly to those which differ from the previously known range of shapes, typical for the respective element.

Following this idea, no consideration is given to technical features necessary for the functionality of the product or for the product's material and internal construction.

Afterwards, once this analysis is completed, the court must compare the over-

${ }^{11}$ Fiat Auto S.PA. v. Great Wall Motors, (2008), Ji Min San Zhong Zi No. 84. The judgment made on December 29, 2008 by Hebei High Court.

${ }^{12}$ Judicial Interpretation of the Supreme People's Court on Several Issues Concerning the Application of Law in the Trial of Patent Dispute Cases Fa Si, (2009), No. 21, which came into effect f January 1, 2010. 
all visual effect of the claimed design with that of the accused product. This crucial phase evaluates the impact of design differences on the overall visual effect of both designs under comparison, including design features which are present in the patented design, but are different or absent from the infringing design.

If the outcome is that there are no differences between the overall visual effects of the patented and the accused designs, the court shall find the designs to be identical. In case the court finds no substantial differences between the two overall visual effects, the court shall find the designs to be similar, which means that minor design differences will not affect the impression of overall visual similarity of the designs under comparison. Therefore in both instances infringement will be found.

In drafting its 2009 Interpretation, the Supreme People's Court's had been influenced also by recent court judgments in China. In particular, a precursor of the December 2009 Interpretation's Article was the decision of the No. 1 Beijing Intermediate Court in the Neoplan v. Zonda case ${ }^{13}$ involving the outer design of a bus.

Indeed, in 2009 German company Neoplan Bus won more than \$3 million in damages after bringing a design patent case against Chinese automotive company Beijing Zhongtong Xinghua (Moga, 2012).

The First Intermediate People's Court of Beijing found that there had been infringement of a bus design. The court, in ruling in favour of Neoplan, ignored "partial and minor" differences that did not impact the overall design of the bus. ${ }^{14}$ The court concluded that the presence of differences in the design does not necessarily keep out the overall effect of actual similarity between the two designs, evoked by the comparison.

The important element of this decision is that, as long as the overall visual effect remains similar, the actual existence of differences will not avoid infringement anyway.

The essentiality of design features must also be determined based on the design's overall visual effect alike.

Neoplan decision as well as Article 11 of the 2009 Interpretation enacted afterwards, have brought a quite massive change of direction: article 11 officially broadened the scope of protection of design patents and especially the plausibility of successful enforcement against attempts to avoid liability by merely changing or by adding design features to a product.

It also foreseen a more objective confirmation test in order to limit the discretion of civil judges when determining a design's essential and non-essential features.

\footnotetext{
${ }^{13}$ Neoplan v. Zonda, (2006), Yi Zhong Min Chu Zi No. 12804, judgment by No. 1 Beijing Intermediate Court in 2009.

${ }^{14}$ In its judgment of January 14, 2009, the court noted that: “[...] both designs are characterized by wedge-shaped upper and lower windshields, [... The above-mentioned design features basically constitute the overall exterior design of the bus. Although there are differences between the two, (...), these are partial and minor and do not obviously affect the overall view of the bus. The accused infringing product and the patented design are almost identical based on overall observation ...”.
} 
This norm thus abandoned the former "element-to-element" comparison standard, in favour of the overall impression of similarity in the eyes of a normal user (Beldiman \& Beconcini, 2015).

In particular, judges are now required to conduct comparisons based on a comprehensive examination of the products and to define the overall visual effect of the protected design by selecting its essential features. Such features are described as innovative and different design features, unique from the typical range of shapes or patterns known for that type of product.

So, the norm stretched the prior boundaries to enlarge the scope of protection of design patents. At the same time, given the need to protect only the design's aesthetic value, the Interpretation requires judges to not take in consideration those features which are not novel, technically needed or too tiny to be relevant (Moga, 2012).

After the 2009 Interpretation entered into force, the Supreme Court had the opportunity to improve the concepts embodied in its Article 11.

Indeed in 2010, in Honda v. Patent Re-examination Board ${ }^{15}$ : another case involving a vehicle, the Supreme Court further defined how the essential features and scope of protection of a design patent are to be determined. In Honda case, the Court attempted to achieve a balance between the holistic assessment based on the test of comprehensive observation of the designs with the need to set aside non-protectable elements, such as non-novel or technically necessary features.

The Supreme Court assumed that in car designs which share or seem sharing a common configuration as a whole (including non-innovative and technically needed shapes), the overall configuration of the vehicle shape will have a limited visual effect and impact at sight of an ordinary observer. On the other hand, distinctions in sectional design features, such as the design of headlights, lateral views, and rear views, generally do have a notable visual effect on the design of the car as a whole.

Based on this argument, the Court ruled that the existence of real differences in specific design features, such as headlamps and side door windows, would lead ordinary consumers to distinguish the patented design from prior designs.

Therefore this decision clearly confirms the enclosed principle in Article 11 of the 2009 Interpretation, requiring a judge to disregard features which are not novel or technically needed from the overall visual effect.

Thus, unlike Fiat Panda case, the Honda decision doesn't state that differences on single design features are sufficient to avoid similarity (Beldiman \& Beconcini, 2015). Firstly, judges have to closely focus on certain relevant features (innovative and unique features) and then to consider their visual effect comprehensively with respect to the rest of the vehicle.

In sum, the Court seems to be seeking a balance between the need to emphasize the predominant essential features and the necessity of avoiding a compari${ }^{15}$ Honda v. Patent Reexamination Board, (2010), Xing Ti Zi No. 3, judgment by Supreme People's Court in China, on November 26, 2010. 
son based on a non-complete design, an approach that would possibly lead to the "element-to-element" comparison.

Therefore, after having identified the overall visual of the essential features, the Court will have to re-examine the design and confirm this effect in light of the overall and comprehensive view of the entire design.

This decision is quite restrictive in reducing the judge's freedom to select what features are essential or not. However, it doesn't seem to restrict the legal value of the comprehensive examination of the whole vehicle including also non-novel parts (or rather for every type of vehicle the "standard" shape). This approach responds to the local Chinese automotive industry's proclivity to take inspiration from individual parts of a foreign design patent and combine them with more common existing designs.

Following the Honda decision, the Supreme People's Court express its opinion again on the issue, regarding how essential features are to be qualified and identified.

In particular, the court confirmed the principle that the overall visual effect of a design patent is determined by its essential features, as it has been stated in Honda and previously in Article 11 of the 2009 Interpretation.

The Supreme Court stated that the addition of new decorative features to the accused design should not automatically prevail on the comprehensive effect of visual similarity, as long as the infringing product design contains all the essential and relevant features of the patent.

In the 2011 Jun Hao Company vs. Jia Yi Furniture Factory decision ${ }^{16}$, the Supreme People's Court improved the concept of design essential features by adding a new criterion of examination, not originally specified by art. 11 of the 2009 Interpretation: a mere addition to the design is not sufficient to avoid liability if such addition has a simply decorative function and does not alter the shape of the claimed design patent. ${ }^{17}$

This precedent was recently upheld in another decision of the Supreme Court of September 22, 2013 in the MAPED SAS v. Yanjiang Bonly Industries case ${ }^{18}$ concerning a design patent for the outer contour of small scissors.

In this decision, the court explained the justification behind the principle stated in Jun Hao decision: an extra design element has no material impact on the similarity of the overall visual effect, as conveyed by the essential features also taken over by the accused product; otherwise, second comers could easily avoid infringement by simply adding colours or patterns to the original design.

\footnotetext{
${ }^{16}$ Zhongshan City Junhao Furniture Co., Ltd. v. Zhongshan City South District Jiayi Craft Furniture Factory, (2011), Min Shen Zi No. 1406, judgment was made by Supreme People's Court in China on November 22, 2011.

${ }^{17}$ The Supreme People's Court stated that: “(...) the design characteristic in design patent which is different from existing design has significant influence on the overall visual effect. In cases in which the accused design uses the design characteristic of the patented design, simple replacement of decorative pattern will not influence the similarity between the two in visual effect (...)."

${ }^{18}$ Yin Xintian, Xu Ying, “SPC's Opinion on Patent Infringement Recognition Involving a Design Patent”, (2014), Legal Studio.
} 
A merely decorative addition to a visual effect that alternatively would be overall identical or similar, explicitly breaches the Patent Law, as well as violates its intent of promoting innovation and development.

In this way, the jurisprudence emerging from the Honda, Jun Hao and MAPED cases seems to follow the early suggested direction by the Beijing Intermediate Court in the Neoplan case and confirmed by the Supreme People's Court in Article 11 of the 2009 Interpretation.

Both Honda and Jun Hao decisions seem to have found a balance in establishing the design's scope of protection and the infringement criterion of evaluation, by adhering to the standard of overall visual examination, nevertheless with some corrections and clarifications depending on the type of products.

In July 2014, the Supreme People's Court issued for public comment a new draft "Interpretation on Several Issues about the Application of the Law to the Trial of Patent Infringement Disputes II"19. This is the Supreme People's Court's second interpretation of the Patent Law, since its latest legislative amendment in 2009.

The Draft follows the proposed amendments to the Patent Law issued by the State Council in August 2012 and more importantly, the "Guidelines for Determination of Patent Infringement" issued in September 2013 by the Beijing Higher Court (“Opinions”). Mainly it provides an insight into the Supreme Court's doctrinal thinking and can actually predict the changes to be made to design patent protection norms in China. Furthermore, it seems to substantially increase the burden of proof of patentees with respect to determination of infringement (Beldiman \& Beconcini, 2015).

On the other hand, clearer interpretations of relevant norms on infringement determination may help consistency and clearness in referring to what can be really protected with regard to design patents.

A more effective judicial certainty can ultimately benefit holders of innovative and truly original design patents, as well as it will have long-term opposite effects only on the "junk" patents registered as designs in China.

Article 17.2 of the Draft provides that where an allegedly infringing product does not reproduce all the features which distinguish the patented product from prior design, the court may presume that the designs are not similar, and therefore not infringing.

On the other hand, there will be a presumption of similarity when all the distinguishing relevant features of the design patent are reproduced in the accused design. This provision is likely to extend the literal infringement theory applicable to invention patents to design patents too (Beldiman \& Beconcini, 2015).

It likely arises out of the Supreme People's Court's desire to set practical rules to facilitate judges' decision-making when assessing infringement in light of Article 11 of the 2009 Interpretation.

The Draft's aim is to reduce the discretionary space of judges when deciding a ${ }^{19}$ Judicial Interpretation of the Supreme People's Court on Several Issues Concerning the Application of Law in the Trial of Patent Infringement Cases, (2016), effective as of April 1, 2016. 
case, and establishing a clearer identity/similarity determination standard. On the other hand, Article 17.2 seems to distance itself not only from Article 11 of the 2009 Interpretation but also from the holding of the Honda decision. In its current formulation, Article 17.2, could be understood as a derogation of the general principle of comprehensive comparison of the overall visual effect of the designs, as it seems to exempt the judge from confirming the essential features identified in the course of the first examination of the patented design by a comprehensive determination of the overall visual effect of the design patent (as provided in the 2009 Interpretation and later in Honda).

This thus can lead to a major risk of erroneous and subjective determinations by a civil judge and a return to the "element to-element" standard, as happened for example in the Fiat Panda case.

However, this provision must be read in light of Honda and Jun Hao and is thus limited to those added features with a mere decorative effect, as mentioned above, since it is stated and true that the essentiality of a feature in a design can only be measured and confirmed by looking at the product's design in its entirety.

Nowadays, China's patent laws are world-class, but on the other hand the challenges involved in enforcement are still noteworthy.

This fact, as well as infringements cases, influences potential foreign design patent applicants to assess many times any plan to file design patent applications, and frequently this leads to abandon such plans (Beldiman \& Beconcini, 2015).

A more flexible approach while interpreting the similarities in design patents would make the Chinese system more attractive to foreign applicants, as well as it would make the system fairer to all design patent holders who are involved in infringement litigations.

In the context of the prior art, the ordinary observer is deemed to spot the differences between the accused product and the patented design, and to recognize whether the differences between the claimed design and the prior art are likely to be pertinent.

In this background, the design patent in China is underutilized by foreign companies, but still it is a valuable and worthy tool that may both protect investments and potentially cease infringements (Moga, 2012).

China has taken several positive steps to improve its design patent protection, however a sustained and focused effort is always required in order to cease uncontrolled counterfeiting and especially to defeat inadequate enforcement.

\section{Patent Protection in the EU-Comparison with China}

\subsection{Patent Law in European Union Law Context}

The European Union (EU) approach has been well-established for many years and its model for many intellectual property law regimes in the world (Man, 2013). 
The EU is an established regime and is mostly laid out in the Treaty on the Functioning of the European Union TFEU.

According to EU law, generally patents have always been considered as a key tool to promote investments in innovation as well as encourage its dissemination.

European Commission unceasingly monitors the necessity for new rules and at the same time also the effects of patent-related legislation across the EU; it is working to introduce a cost-saving, adequate, consistent patent protection across Europe, as well as it's constantly looking at efficient measures to enhance patent exploitation.

The starting point as regards the protection of patents in Europe is the European Patent Convention ${ }^{20}$, an intergovernmental agreement among 38 European states, including all 27 EU member states ${ }^{21}$.

This Convention establishes a procedure for obtaining a 'European patent', following a single application to the European Patent Office (EPO) established by the Convention.

The patent granted by the EPO is only valid as regards the states for which it is granted, and the patent in question must then be validated in each of the states in which protection is sought.

Moreover, with the entry into force of the Treaty of Lisbon on 1 December $2009^{22}$, the legal basis for some of the measures, related to intellectual property rights as well, changed. Article 118 of the Treaty on the Functioning of the European Union (TFEU), the new name for the former EC Treaty, confers explicit power to "establish measures for the creation of European intellectual property rights to provide uniform protection of intellectual property rights throughout the Union and for the setting up of centralized Union-wide authorization, co-ordination and supervision arrangements." ${ }^{23}$ The applicable decision-making rule is now the "ordinary legislative procedure" (TFEU, art. 18).

According to EU law, a patent is technically a legal title that can be granted for any invention having a technical character, provided that it is new, involving an "inventive step", and is susceptible to industrial application: it can cover how things work, what they do, what they are made of and how they are made (Peers, 2011).

Patents generally grant the owner the right to prevent others from making,

\footnotetext{
${ }^{20}$ There is a lengthy history of unsuccessful attempts to harmonize patent law in the EU, beginning in the 1950s and 1960s. 22 Eventually in 1976, after agreement on the EPC, the EU member states agreed an intergovernmental Convention establishing a Community patent (the Luxembourg Convention), but this was not ratified.

${ }^{21}$ The Convention has been signed in 1973 and amended in 2000. The original EPC was opened for signature on 5 Oct. 1973 and entered into force on 7 Oct. 1977; the amendments were opened for signature on 29 Nov. 2000 and entered into force on 13 Dec. 2007.

${ }^{22}$ The Treaty of Lisbon is an international agreement that amends the two treaties which form the constitutional basis of the European Union. The Treaty of Lisbon was signed by the EU member states on 13 December 2007, and entered into force on 1 December 2009.

${ }^{23}$ Also, the Treaty of Lisbon merged the EC and the EU (Art. 1 of the Treaty on European Union (TEU), third para.).
} 
using or selling the invention without permission. Moreover, patents are a means to encourage companies to make the necessary investment for innovation, and provide the incentive for individuals and companies to bestow more resources to research and development. On the other hand, patents inevitably imply the disclosure of the protected invention: but this fosters the dissemination of innovation as well.

Currently, technical inventions can be protected in Europe either by national patents, granted by the competent national IP authorities in EU countries or by European patents granted centrally by the European Patent Office.

Since the EU is a party to the $\mathrm{WTO}^{24}$, the Court of Justice has jurisdiction to interpret the TRIPs ${ }^{25}$, to the extent that such interpretation can be linked to legislation adopted by the EU. However, as regards patents, the Court implicitly does not have much jurisdiction to interpret the substantive TRIPs rules, as long as the EU legislation on this issue remains limited in scope. In case these rules can actually be linked to specific EU patent legislation, the EU legislation must be interpreted in light of those rules.

Furthermore, while WTO rules generally don't confer direct effects in the EU legal system, it's EU member States' decision to determine the legal effect of those rules where the EU has not yet legislated (in many cases patent issues).

According to EU law, patent protection currently can be obtained in three ways (Ceranic, 2017): first, through national patent offices, which grant national patents based on the national patent law valid for the respective national territory; second way is by the European Patent Office ${ }^{26}$, which grants European patents based on the European Patent Convention; third way is on the basis of Patent Cooperation Treaty, under which only the procedure of examination of patentability of inventions is centralized, whereas patents are generally granted by national patent offices.

Under the EPC, the contracting states transfer their sovereign right to examine a patent application and to grant a patent with effect for their territory to an intergovernmental organization, the European Patent Organization (EPO). In this way, through a single application, a patent and its related protection can be obtained in all EPO Member States. However, once a European patent is granted by the European Patent Office for all Member States, it has to be validated in each EPO Member State for which protection has been looked for.

\subsection{Design Patents in EU}

The design law of the European Union came to the scene relatively recently (Peers, 2011).

Developed in the late 1990s, the EU design law system has sought to avoid the problems that plagued older design laws in the EU member states and in other legal systems as well.

${ }^{24}$ World Trade Organization.

${ }^{25}$ TRIPS Agreement, see n.3.

${ }^{26}$ European Patent Office website http://www.epo.org/. 
When determining a patent infringement, in EU system, the infringement analysis differs from the analysis in China, as discussed previously.

Infringement is measured by whether the allegedly infringing product does or does not "produce on the informed user a different overall impression" from the protected relevant design (Beldiman \& Beconcini, 2015).

The differences between a protected design and an accused article are assessed by the "informed user", who is a user having experience of other similar articles, able to appreciate enough detail to decide whether an alleged infringement produces a different overall impression.

In this context, the informed user is precisely a user of the product, not a designer, nor a technical expert or manufacturer or seller, but an observant user, being able to detect essential differences to the overall impression, which the average consumer does not see, since the informed user is interested in the concerned products by showing also a relatively high degree of attention when he uses them, as well as recognizing capability while choosing them.

EU law has set the assessment of both the prior art and of functional features into a single process: the evaluation by the informed user of both these aspects. Thus, the informed user is the one who can carry out this evaluation, not only with regard to the design, but also concerning technical features.

When assessing similarity, the informed user is required to take into consideration "the degree of freedom of the designer in developing his design".

Freedom of design may be restricted in particularly scopes where products have a rich design corpus (prior art). The informed user is deemed to have knowledge of the design corpus, as well as of the design features normally included in the existing designs in the respective sector.

Thus, a comparison between the claimed and the accused design takes into consideration that a particular field is very busy, and it allocates appropriate evaluation to related products: when the field is crowded minor differences may sufficiently differentiate among designs (Beldiman \& Beconcini, 2015).

Moreover, in this context further restrictions on the designer's freedom may result from the fact that design features are closely linked to the specific functions of products.

In such cases, when technical or functional constraints basically limit the designer's scope of freedom, competitors' designs inevitably tend to closely resemble the protected design.

Thus the informed user must take into account the degree of the designer's freedom and possible variations within the related product field. In his analysis, the informed user must recognize that the relevant scope of protection of designs where a designer has a little level of freedom will be narrower than for other designs; conversely, when the designer enjoys a high degree of freedom, a greater scope of protection is consequently accorded to the design. Accordingly, this process does not require functional features to be excluded.

As an example, in Gimex v. The Chill Bag, ${ }^{27}$ which involved the design of bot-

${ }^{27}$ Gimex Int'l v. The Chill Bag \& Ors., (2012), EWPCC 31. 
tle bags, the court had determined that many features of the design's functional considerations necessarily impose design constraints.

In this case the court didn't deem the entire design invalid pursuant to Article $8(1),{ }^{28}$ nor it excluded the relevant functional features. The court, taking in consideration all related aspects, pointed out that the functional nature had already been taken into account when considering design freedom: in this way, based on the claimed design as a whole, the court then proceeded to make the comparison considering the features' functional nature as well.

In this cited case, because of the presence of numerous functional features, the bottle bags were quite similar, with the general effect that the scope of protection was relatively narrow: consequently the accused product was considered infringing the relevant patent.

\subsection{Comparative Aspects with China}

This comparison involves two different legal systems owning specific roots and traditions about intellectual property related rights, and simultaneously laws.

China shows a tradition where the concept of intellectual property rights came quite late, both relevant laws and the effective protection of such rights.

The above-mentioned context and tradition in China acquired a very high importance in the past, which also affected regulations, as highlighted in the previous paragraphs.

The current relevant interpretations seem to be seeking a balance between the need to emphasize the predominant essential features and the necessity of avoiding a comparison based on an "element-to-element" comparison, that might lead to exclude infringements easily.

The latest Draft's aim is to reduce the discretionary space of judges when deciding a case, and establishing a clearer identity/similarity determination criterion, especially in the case of presence of mere decorative elements in certain patents application, that might mislead judges when determining infringements.

The purpose of the latest regulation is that Courts, when deciding a case, ascertain that the essentiality of a feature in a design is measured and confirmed by looking at the product's design in its entirety.

Comparing this perspective with EU law an essential difference can be found: as highlighted above, the differences between a protected design and an accused article are assessed by the "informed user", which is required to take into consideration the degree of freedom of the designer in developing his design and, since it is required to be "informed", has a deeper knowledge as well as experience regarding the subject matter, unlike an "ordinary user", which has been used as a reference by Chinese courts at first.

Furthermore, it's fundamental the difference regarding the analysis method, that according to the relevant procedures in the EU, an infringement is measured by whether the allegedly infringing product does or does not produce to the ${ }^{28}$ Council Regulation (EC) No. 6/2002 of 12 December 2001 on Community Designs Article 8(1) provides that "A Community design shall not subsist in features of appearance of a product which are solely dictated by its technical function." 
informed user a different overall impression from the protected relevant design, where the overall impression matters, rather than an element-to-element analysis, which has been used as a method by Chinese courts. The overall impression includes not only the appearance, but also the technical features of the concerned patent: in this way the infringement analysis would be more accurate, and it would lead to a precise evaluation.

Moreover, a very relevant difference concerns the procedure of obtaining a design protection: in Europe there are two forms of protection: Unregistered Community Design (UCD) and a Registered Community Design (RCD ${ }^{29}$, which both cover the whole of the EU (protection is also provided on a national level but terms vary across the EU), whereas in China designs must be registered as design patents in order for them to be protected, therefore provisions of the Chinese Patent Law must be applied (China IPR SME Desk, 2012).

In EU an UCD means that any design made available to the public is protected from being copied for three years from the date of publication. If a longer term of protection is preferable, designs can be formally registered as an RCD with the European Union Intellectual Property Office (EUIPO).

Conversely, a Chinese design patent provides exclusive use of the aesthetic features of a product, and when applying for a design registration in China, the design must comply with the novelty requirement: the design must be new and not have been disclosed to the public through sales, advertising or any other means anywhere in the world before the application is filed in China.

If the design was disclosed before the design patent application was filed, the patent could be invalidated later.

This rule means that a design that has been published and enjoys UCD protection in Europe could not receive a design patent in China, since it has already been made available to the public domain.

This provision is really important for foreign companies in China. Indeed, in order to obtain a design patent protection in China, a foreign company, European ones as well, has to file a Chinese patent application in China.

Otherwise, for instance EU companies can file a patent application first in a EU country and then file a patent application in China within six months, claiming the priority date of the first application.

Currently there is a third way for obtaining a wider protection: companies may file an international patent application under the Patent Cooperation Treaty ${ }^{29}$ China IPR SME Desk, (2012), Design Patent Guide.

${ }^{30}$ Patent Cooperation Treaty: is an international patent law treaty, concluded in 1970. It assists applicants in seeking patent protection internationally for their inventions, helps patent Offices with their patent granting decisions, and facilitates public access to a wealth of technical information relating to those inventions. By filing one international patent application under the PCT, applicants can simultaneously seek protection for an invention in a very large number of countries. A PCT application does not itself result in the grant of a patent, since currently there is no "international patent", and the grant of patent is a prerogative of each national or regional authority: indeed a PCT application, which establishes a filing date in all contracting states, must be followed up with the step of entering into national or regional phases to proceed towards grant of one or more patents. The PCT procedure essentially leads to a standard national or regional patent application, which may be granted or rejected according to applicable law, in each jurisdiction in which a patent is desired. 
$(\mathrm{PCT})^{30}$, naming China as one of the designated states. This kind of application can be filed with the European Patent Office or any national patent office within the EU.

In such case, the applicant in China has to initiate the "national phase", the procedure with SIPO, no later than 30 months from the priority date.

\section{Conclusion}

Even though China doesn't have a very long and well established tradition with regards to IP matters, as European Union does, in the latest years China has been improving and enhancing IP laws and regulations, with the aim to become a country with a first class IP rights protection.

By improving the IP system, especially with regards to settling disputes, both local and foreign companies would benefit from a progressed legal background where IP rights are efficiently protected and encouraged.

\section{Conflicts of Interest}

The author declares no conflicts of interest regarding the publication of this paper.

\section{References}

Beldiman, D., \& Beconcini, P. (2015). The Final Impression Counts-Seeking Common Ground in Design Patent Infringement. J. Pat. \& Trademark Off. Soc'y, 97, 551.

Ceranic, J. (2017). The Unified Patent Court: A New Judicial Body for the Settlement of Patent Disputes within the European Union, 1 ECLIC 238.

Crouch, D. D. (2010). A Trademark Justification for Design Patent Rights. In Legal Studies Research Paper Series. Research Paper Number 2010-17, School of Law University of Missouri.

Huang, K. G., Geng, X., \& Wang, H. (2017). Institutional Regime Shift in Intellectual Property Rights and Innovation Strategies of Firms in China. Organization Science, $1-41$.

Li, J. J., \& Su, C. (2007). How Face Influences Consumption: A Comparative Study of American and Chinese Consumers. International Journal of Market Research, 49, 251-252.

Man, Y. N. (2013). Intellectual Property Law and Competition Law in China: Analysis of the Current Framework and Comparison with the EU Approach. IALS Student Law Review, 1, 28-48.

Moga, T. T. (2012). Obtaining and Enforcing Design Patents in China. China Business Review, 28-31.

Ou, Y. E. (1996). The Practice of Patent Law in China: Some Firsthand Observations. Wis. Int'l L.J. 15, 313.

Peers, S. (2011). The Constitutional Implications of the EU Patent. European Constitutional Law Review, 7, 229-266.

Raustiala, K., \& Sprigman, C. J. (2014). Let Them Eat Fake Cake: The Rational Weakness of China's Anti-Counterfeiting Policy. Economics Research Paper Series Working Paper No. 15-02, University of California, Los Angeles UCLA.

Timoteo, M. (2010). La difesa di marchi e brevetti in Cina, Percorsi normative in un 
Sistema in transizione, Giappichelli.

Tze-Hun Chou, T. (1997). Private Copyright Investment in China, Westlaw. J. SMALL \& EMERGING BUS. L., 1, 375, 393.

Yu, P. K. (2018). A Half-Century of Scholarship on the Chinese Intellectual Property System. American University Law Review, 67, 1045-1140. 